\title{
The Pattern of Water Flow in A Tidal Pond, Macro Water System on the Tidal Farms with Numerical Hydrodynamics Model Approach: A Case Study Of Tidal Farm In South Kalimantan
}

\author{
Achmad Rusdiansyah ${ }^{1, *}$, Hafiizh Prasetia ${ }^{2}$ and Nova Annisa $^{2}$ \\ ${ }^{1}$ Department of Civil Engineering, Faculty of Engineering, Lambung Mangkurat University \\ ${ }^{2}$ Department of Environmental Engineering, Faculty of Engineering, Lambung Mangkurat University
}

\begin{abstract}
The water flow pattern and velocity caused by tidal water and the effect of wind in the tidal pond can be examined by developing a 2-D Hydrodynamic numerical model. The numerical model is based on the continuity equation and the 2-D momentum equation, these two equations are solved by finite different methods which are explicit Mac. Cormack. The validity of the model was tested with a numerical model experiment that is a 2-D water flow model simulation in a flow field in the form of a rectangular and rectangular pond water flow pattern. The application of this model will be carried out on tidal ponds, and is expected to provide satisfactory results.
\end{abstract}

\section{Introduction}

The island's coastal zone in Indonesia is largely an area of vast land that is still not productive. There have been many efforts carried out in the framework of its utilization, such as the business in the fields of plantation, agriculture and fisheries. Fisheries in coastal areas with low topography are lands that are affected by tidal water.

In an effort to develop fisheries land in coastal areas, one of the uses of tidal land for fisheries is carried out by tidal water control, this control is known as the one way or two way system. This system has a multifunctional system, one of which is excess water at high tide can be accommodated and waste water can be discharged at low tide, it is channeled back to the estuary with the aim of circulating water, where tidal water flows carry a mass of fresh water and at low tide the water can be pushed along with water polluted. This water pollution occurs because of the presence of nutrients, ammonia and other pollutant elements in tidal pond waters such as sediments which are always moving along the water flow and some settle which make the tidal pond sink and can disrupt water circulation.

Tidal ponds which are shallow and relatively wide waters with the nature of unsteady non uniform flow, with speed and direction change with time and space, where the

*Corresponding author: achmadrusdiansyah@ymail.com 
movement of water flows in the tidal pond is an input process of tidal water wind gusts. Therefore the element / substance content of water quality parameters at each point on the flow field will be uneven, always changing and depending on changes in water flow velocity that occur during high tide, low tide, and due to wind gusts.

Theoretically the results of the measurement of water flow velocity in the field will be accurate if measured every interval of a certain distance and in a certain time interval during the tide, ebb, and due to wind gusts. But this method requires a relatively large time and cost. One alternative that is economical in monitoring the flow pattern and speed in the tidal pond is to develop a numerical hydrodynamic model[1][2].

\section{Methods}

\subsection{Research Design}

Regulatory equation uses the law of mass and energy rigidity, namely continuity and twodimensional momentum. The continuity and momentum equations are solved by the finite different explicit Mac Cormack approach. Mac Cormack's explicit method cannot resolve the upstream and downstream boundary conditions, then it is solved by the Characteristics method. The input data entered is the initial conditions, boundary conditions and channel geometry. Data on initial conditions and flow limit conditions, namely the depth of tidal water $\mathrm{H}$. From the above stages, a hydrodynamic model is developed, using fortran language.

By entering a variable speed of wind speed, produces an energy on the surface of the water. Energy surface water is expressed by surface shear stress. By inputting the tidal depth as the upper boundary condition, the model simulation can be run. The hydrodynamic model simulation can be run (running program) with tidal data input and the influence of wind, resulting in a speed in the flow field. With the help of software (transform spyglass) the results of model simulation data can be described in the form of velocity water flow patterns. The velocity water flow pattern is expressed in the form of velocity vector with the known magnitude and direction[3][4][5][6][7][8].

\subsection{Data Analysis}

Regulating equation is a partial diffrential equation, namely continuity and momentum equations which are solved numerically by the difference method up to, using the method of explicit method Mac Cormack[9]. The hydrodynamic equation in this case the continuity $\&$ momentum equation is solved by the explicit and finite difference method used based on the Mac Cormack scheme. This method consists of the Predictor step and the Corrector step and then the solution step, solving the following equation[10][11].

\section{The Equation Of Continuity:}

$$
\begin{gathered}
\frac{\partial H}{\partial t}=-\frac{\partial}{\partial x}(q x)-\frac{\partial}{\partial y}(q y) \\
\frac{H_{i, j}^{n+1}-H_{i, j}^{n}}{\Delta t}=-\frac{q x_{i, j}^{n}-q x_{i-1, j}^{n}}{\Delta x}-\frac{q y_{i, j}^{n}-q y_{i, j-1}^{n}}{\Delta y} \\
H_{i, j}^{n+1}=H_{i, j}^{n}-\frac{\Delta t}{\Delta x}\left[q x_{i, j}^{n}-q x_{i-1, j}^{n}\right]-\frac{\Delta t}{\Delta y}\left[q y_{i, j}^{n}-q y_{i, j-1}^{n}\right]
\end{gathered}
$$


The Predictor Step:

Step Correktor:

$$
\widetilde{H}_{i, j}=H_{i, j}^{n}-\frac{\Delta t}{\Delta x}\left[q x_{i, j}^{n}-q x_{i-1, j}^{n}\right]-\frac{\Delta t}{\Delta y}\left[q y_{i, j}^{n}-q y_{i, j-1}^{n}\right]
$$

The Final Step:

$$
\overline{\bar{H}}_{i, j}=\widetilde{H}_{i, j}-\frac{\Delta t}{\Delta x}\left[\widetilde{q x}_{i+1, j}-\widetilde{q x_{i, j}}\right]-\frac{\Delta t}{\Delta y}\left[\widetilde{q}_{i, j+1}-\widetilde{q y}_{i, j}\right]
$$

$$
H_{i, j}^{n+1}=0,5\left[H_{i, j}^{n}+\overline{\bar{H}}_{i, j}\right]
$$

The X-Direction Momentum Equation:

$$
\begin{gathered}
\frac{\partial}{\partial t}(U H)+\frac{\partial}{\partial x}(\beta U U H)+\frac{\partial}{\partial y}(\beta U V H)=-g H \frac{\partial H}{\partial x}-g H(S o x+S f x) \\
\frac{q x_{i, j}^{n+1}-q x_{i, j}^{n}}{\Delta t}=-\left(\frac{\partial}{\partial x}\left(q x \cdot \frac{q x}{H}\right)+\frac{1}{2} g H^{2}\right)-\frac{\partial}{\partial y}(q x . q y / H)-g H(S o x+S f x)
\end{gathered}
$$

The Predictor Step:

$$
\begin{aligned}
\widetilde{q x}_{i, j}=q x_{i, j}^{n}- & \frac{\Delta t}{\Delta x}\left[\left(\frac{q x_{i, j}^{n} q x_{i, j}^{n}}{H_{i, j}^{n}}+\frac{1}{2} g H_{i, j}^{n} H_{i, j}^{n}\right)-\left(\frac{q x_{i-1, j}^{n} q x_{i-1, j}^{n}}{H_{i-1, j}^{n}}+\frac{1}{2} g H_{i-1, j}^{n} H_{i-1, j}^{n}\right)\right] \\
& -\frac{\Delta t}{\Delta y}\left[\left(\frac{q x_{i, j}^{n} q y_{i, j}^{n}}{H_{i, j}^{n}}-\frac{q x_{i, j-1}^{n} q y_{i, j-1}^{n}}{H_{i, j-1}^{n}}\right)\right] \\
& -\Delta t g\left[\operatorname{Sox}+q x_{i, j}^{n} \frac{\sqrt{q x_{i, j}^{n} q x_{i, j}^{n}+q x_{i, j}^{n} q x_{i, j}^{n}}}{C h e z y_{i, j}^{2} H_{i, j}^{n 2}}\right]
\end{aligned}
$$

Step Correktor :

$$
\begin{aligned}
& \overline{\overline{q x}}_{i, j}={\widetilde{q x_{i, j}}}_{i=}-\frac{\Delta t}{\Delta x}\left[\left(\frac{{\widetilde{q x_{i+1, j}}}_{i} \widetilde{q x}_{i+1, j}^{n}}{\widetilde{H}_{i+1, j}^{n}}+\frac{1}{2} g \widetilde{H}_{i+1, j}^{n} \widetilde{H}_{i+1, j}^{n}\right)-\left(\frac{\widetilde{q x}_{i, j}^{n} \widetilde{q x}_{i, j}^{n}}{\widetilde{H}_{i, j}^{n}}+\frac{1}{2} g \widetilde{H}_{i, j}^{n} \widetilde{H}_{i, j}^{n}\right)\right] \\
& -\frac{\Delta t}{\Delta y}\left[\left(\frac{\widetilde{q x_{i, j+1}^{n}} \widetilde{q y}_{i, j+1}^{n}}{H_{i, j+1}^{n}}-\frac{\widetilde{q x}_{i, j}^{n} \widetilde{q y}_{i, j}^{n}}{\widetilde{H}_{i, j}^{n}}\right)\right]
\end{aligned}
$$

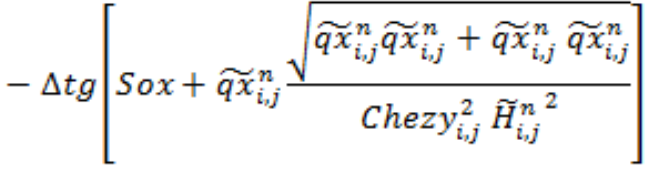

The Final Step:

$$
q x_{i, j}^{n+1}=q x_{i, j}^{n}+\overline{\overline{q x}}_{i, j}
$$




\section{Results and Discussion}

\subsection{Experimental Model}

The validity of the numerical model of the Mac Cormack method was tested by the experimental model (1). Tests with 2-D numerical models are carried out on a rectangularshaped flow field with a solid wall boundary condition. The movement of the water flow is generated by the wind blowing diagonally in the flow field. The simulation results are satisfactory by obtaining a flow pattern with symmetrical velocity vectors and can achieve steady state conditions (Fig. 1).

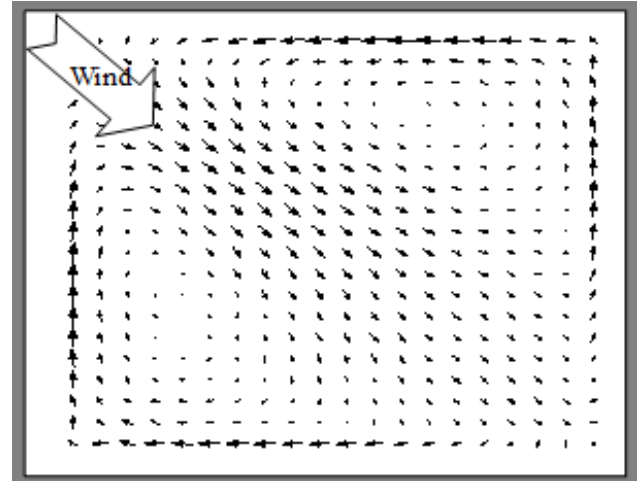

Fig. 1. Water Flow 2-D Patterns in Rectangular Flow Field

Model experiment (2) Test with a 2-D numerical model which is carried out on a rectangular flow field with a solid wall boundary condition. The movement of the water flow is generated by the wind blowing diagonally. The simulation results are satisfactory by obtaining a flow pattern with symmetrical velocity vectors and can achieve steady state conditions (Fig. 2).

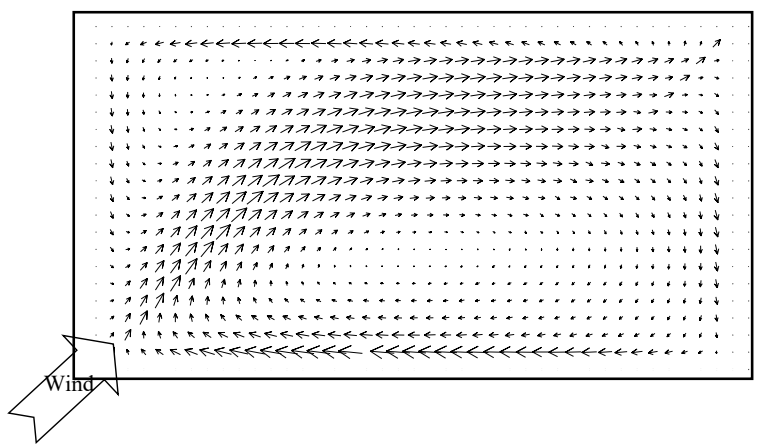

Fig. 2. The Pattern Of Water Flow, Wind Direction Diagonal Rectangle Ponds (Scale Force : $\rightarrow=0.05 \mathrm{~ms}^{-1}$ )

Model experiment (3) experimental test of this model, with cases resembling field conditions, namely the simulation of a rectangular pond flow model with the influence of tidal water. Hydraulic parameter data input (field data) as follows:

- The tidal pond $=(50 \times 100) \mathrm{m}^{2}$ 
- Average depth $(\mathrm{H})=1.0 \mathrm{~m}$

- The width of the channel inflow water $=10 \mathrm{~m}$

- Wind speed $(\mathrm{Va})=4.0 \mathrm{~ms}^{-1}$

This model simulation is carried out in 3 conditions like Fig. 3. This case model aims to find out the water flow line trajectory patterns that will occur and in accordance with predictions.

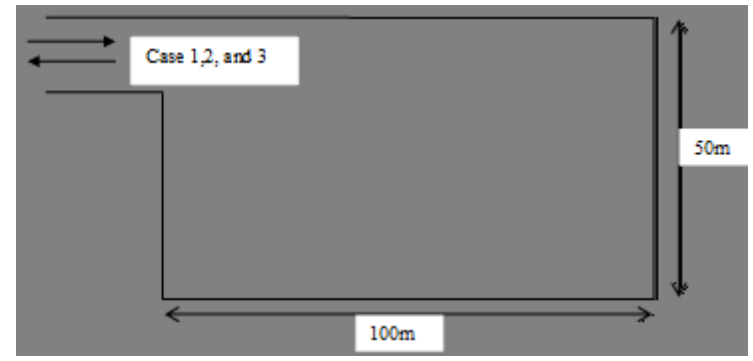

Fig. 3. Simulation of Water Flow and Wind Direction in The Land Outdoor Pair

Description :

Case 1 : The pattern of water flow, tide

Case 2 : Water flow pattern transition of the tide receding moves

Case 3 : Receding water flow patterns

\subsection{The Results Of The Simulation}

The simulation results of cases 1-3, the water flow pattern with the tide input (Fig. 4), the pattern of the water flow transition from tide to low tide (Fig. 5), and the water flow pattern with the tidal water movement (Fig. 6).

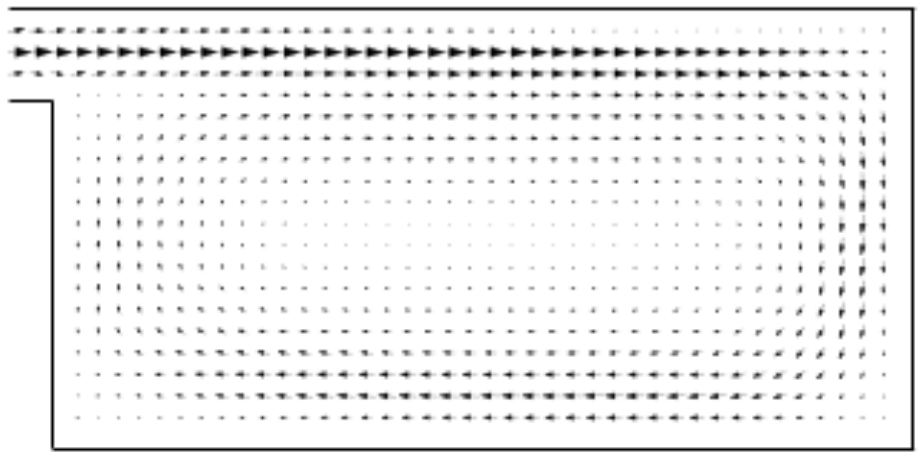

Fig. 4. The Pattern of Flow of The Input with The Tide (Iteration 11 Hours)

(Scale Force $: \rightarrow=0,36 \mathrm{~ms}^{-1}$ ) 


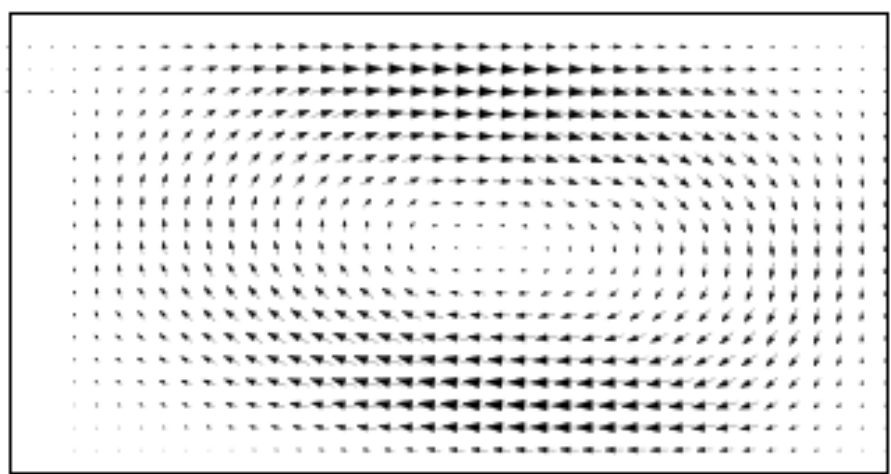

Fig. 5. Flow Pattern Transition of Tide to Recede (Iteration 12 Hours)

(Scale Force : $\rightarrow=0,08 \mathrm{~ms}^{-1}$ )

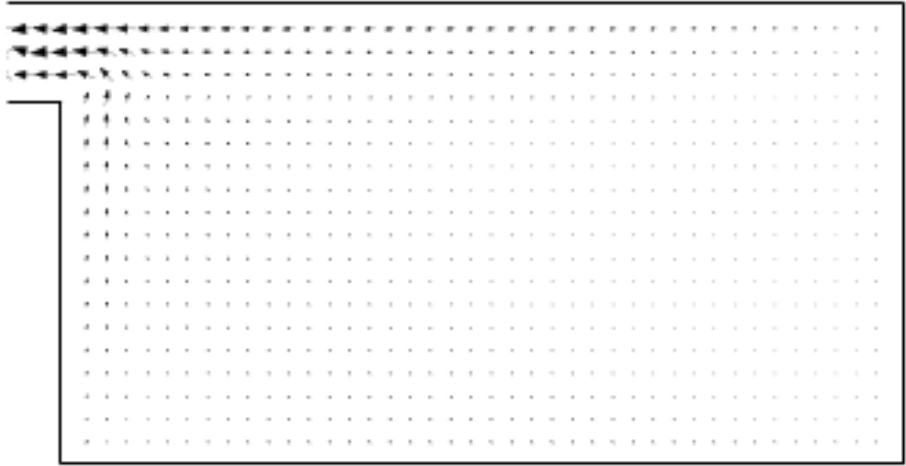

Fig. 6. Receding Water Flow Patterns (Iteration 22 hours)

(Scale Force : $\rightarrow=0,38 \mathrm{~ms}^{-1}$ )

\subsection{The Case is Discussed}

After simulating the experimental model, the model was used to model the water flow pattern in tidal farm tide ponds $(200 \times 250) \mathrm{m}$ with a case study of Tidal Terantang farming in Barito Kuala District (Fig.7). 


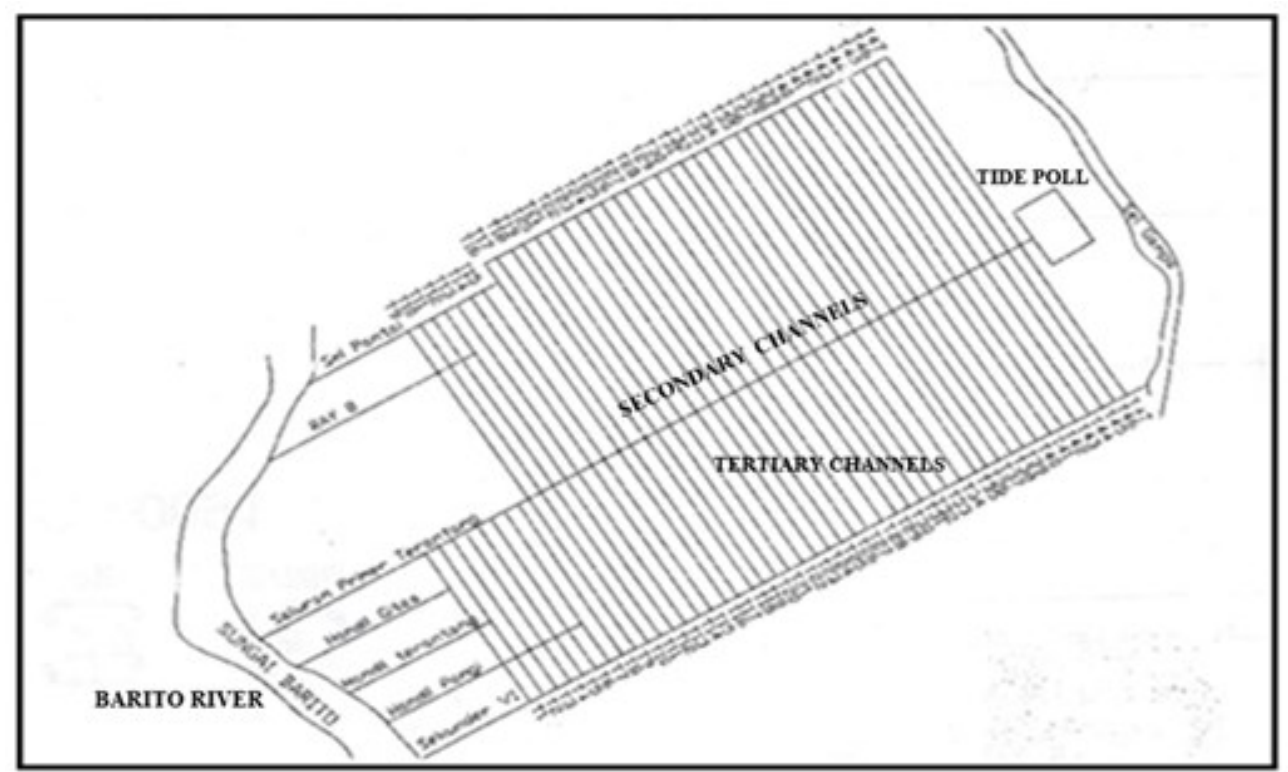

Fig. 7. Tidal Terantang Agriculture In The Barito Kuala Regency

Hydrodynamic model simulation in the tidal pond by modeling several conditions, conditions (1) high tide, condition (2) low tide, condition (3) high tide with the influence of wind gusts. The simulation results are as follows, Fig. 8, Fig. 9, Fig. 10, and Fig. 11.

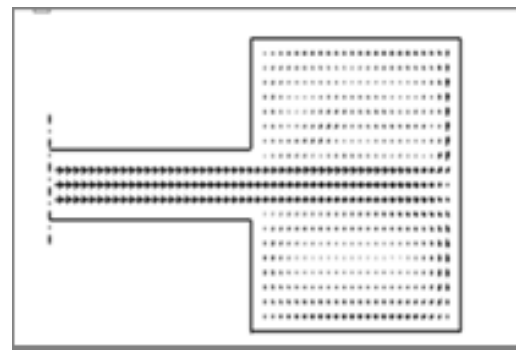

Fig. 8. The Pattern of Motion Trajectory of Line Flow Tide in Tidal Ponds $\quad$ Vmax $=0,21 \mathrm{~ms}^{-1}$

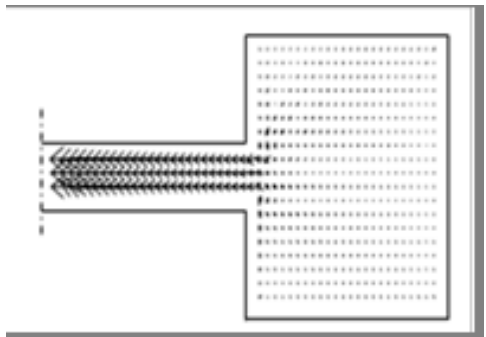

Fig. 9. The Pattern of Motion Trajectory of A Line Water Flow Of Water Receding in Tidal Ponds $\mathrm{Vmax}=0,40 \mathrm{~ms}-1$ 


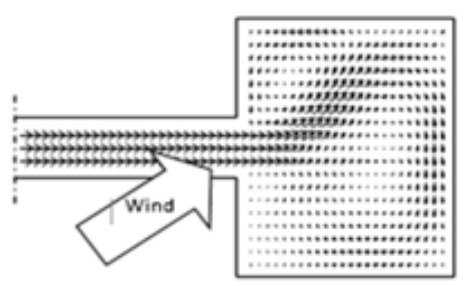

Fig. 10. The Pattern of Motion Trajectory of a Line Water Flow of The Tide and The Wind in Tidal Ponds Vmax $=0,46 \mathrm{~ms}-1$

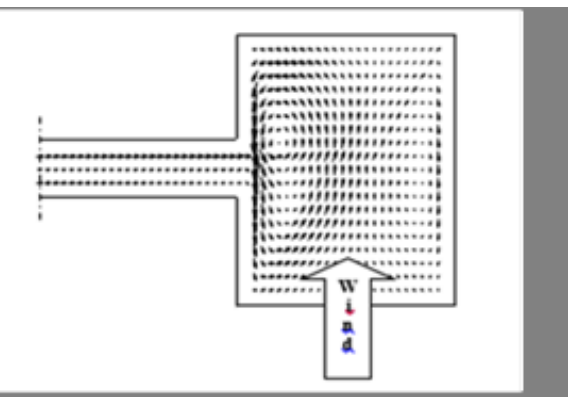

Fig. 11. The Pattern of Motion Trajectory Line of Tidal and Wind Direction Perpendicular in Tidal Ponds Vmax $=0,31 \mathrm{~ms}^{-1}$

\section{Conclusion}

From the results of the experimental simulation and application model (the case discussed) above it can be concluded as follows:

\section{A. Experimental Model :}

1. In the experimental treatment model point 3.1. conditions of solid boundary conditions and point 3.2. the condition of open boundary conditions, where the simulation results are reflected in the velocity vector with a force scale that states the maximum speed. The length or short size of the velocity vector is the large and small water flow velocity that occurs in the pond.

2. In a rectangular sized pond with a solid wall boundary condition, the water flow pattern with the velocity generated by the wind diagonally (Fig. 1), the movement pattern of the trajectory of the water flow line moves diagonally according to the direction of the wind blowing and then turns straight parallel to the solid wall, partially rotates and partially reverses direction on the original trajectory. The movement of this trajectory results in a semicircular pattern and with steady state conditions.

3. In a rectangular-sized pond with a solid wall boundary condition, the water flow pattern with the velocity generated by the wind diagonally (Fig. 2), the movement pattern of the trajectory of the water flow line moves in a diagonal direction in the direction of the wind blowing and then turns, straight parallel to the side solid wall, until the rotating end turns direction on the original track. The movement of this trajectory results in a semicircular pattern and with steady state conditions.

4. In experiment 3 with the open boundary boundary condition for tide input. The movement of water is generated by the tide and the trajectory of the water flow line moves rotates regularly according to the available space. At the time of 
starting to install low speed an average of $0.26 \mathrm{~ms}^{-1}$ and at high tides the speed increases by an average of $0.36 \mathrm{~ms}^{-1}$ (Fig. 4).

5. Movement of the transition water flow from tide to low tide in a pond with a water flow pattern that rotates around the center of the pond with an average speed of $0.08 \mathrm{~ms}^{-1}$. (Fig. 5). This water flow pattern will slowly change with the speed trajectory that moves towards the inlet / outlet direction with the maximum speed on the channel of Vmax. $=0.38 \mathrm{~ms}^{-1}$, like Fig. 6 .

\section{B. The Application Model (Case Covered)}

Based on the results of a simulation model of the cases discussed

1. The water flow line pattern moves correctly according to the available space and semitris either at high tide or low tide like Fig. 8 and Fig. 9.

2. The water flow line pattern with the influence of wind gusts, the water flow moves with the correct water flow line according to the direction of the wind gust like Fig. 10 and Fig. 11.

3. Based on the results above simulations (experiments and the application model) that approach to modeling of hydrodynamics in a 2-D on tidal flow with relatively shallow water depth conditions, can be use for other shallow water applications.

4. Basically hydrodynamic modeling is part of water quality modeling, namely the validity of the water quality model depending on the validity of the hydrodynamic model.

5. Empirically, the patterns of water flow lines obtained from hydrodynamic modeling can predict transport patterns of transport pollutants, sedimentation patterns, BOD, COD, and DO.

\section{References}

1. J. Ganasut and S. Weesakul, "Hydrodynamic Modeling of Songkhla Lagoon Thailand," J.Sc.Tech, vol. 10, no. 5, pp. 32-46, 2005.

2. W. Graf and H. M. Clifford, "Hydrodynamics of Lakes," Elsevier Sci. Publ. Co., 1979.

3. K. Mahmood and V. Yevjevch, Unsteady Flow in Open Channel. USA: Waters Resources, 1975.

4. S. M. Libell and G. Pacini, Application of a Two-dimensional Hydrodynamic Model for Shallow Waters to the Orbetello Lagoon. Italy: Departement of Systems and Computers. University of Florence, 2002.

5. L. C. V. Rijn, Principles of Fluid Flow and Surface Water in Rivers Estuary. Nederland: Seas and Oceans, 1990.

6. L. Makrup, The Basics of Analysis of Flow in Rivers and Estuaries. Jogjakarta: UII Press, 2001.

7. A. James, An Introduction to Water Quality Modelling. England: John Willey \& Sons, 1993.

8. M. B. Abbott, Computational Hydraulic: Element of The Theory of Free Surface Flows. London: Pitman, 1979.

9. Cahyono, Modeling Water Quality in The River, Estuary and Sea, Computer Modelling and Simulation Courses. Bandung: Bandung Institute Of Technology, 1993.

10. A. S. of C. Engineers, "Journal of Hydraulics Engineering," vol. 116, no. August, 1990.

11. J. A. Cunge, F. M. Holley, and A. Verwey, Practical Aspects of Computational River Hydraulics. London: Pitman, 1980. 